\title{
Exploring the Potential for Technology-Based Nutrition Education Among WIC Recipients in Remote Alaska Native Communities
}

\author{
Julianne M. Power, MS ${ }^{1}$; Kathryn L. Braun, DrPH ${ }^{2}$; Andrea Bersamin, PhD ${ }^{1}$
}

\begin{abstract}
Objective: Estimate media technology use in Alaska Native communities to inform the feasibility of technology-based nutrition education.

Methods: A self-administered questionnaire was mailed to a random selection of about $50 \%$ of Special Supplemental Nutrition Program for Women, Infants, and Children (WIC) authorized representatives in remote Alaska Native communities $(\mathrm{n}=975)$. Media technology use, interest in media technology-based nutrition education, and potential barriers were assessed. Chi-square tests were used to investigate associations among technology use, age, and education.

Results: Technology use was common among respondents $(\mathrm{n}=368)$; use was significantly more common among younger age groups and participants with a higher level of education. Smartphone $(78.8 \%)$ and Facebook $(95.8 \%)$ use was comparable to national averages, but having a computer at home $(38.4 \%)$ was much less likely. Less than $50 \%$ of participants have Internet access at home.

Conclusions and Implications: Findings shed light on new opportunities for WIC and other programs to deliver nutrition education to Alaska Native people in remote communities.

Key Words: nutrition education, Alaska Native, eHealth, WIC, social media (J Nutr Educ Behav. 2017;49:S186-S191.)

Accepted November 15, 2016.
\end{abstract}

\section{INTRODUCTION}

American Indians and Alaska Native people have the highest prevalence of diabetes and obesity compared with any other ethnic group in the US, despite a historic rarity. ${ }^{1,2}$ One explanation for this shift is increased consumption of highly processed, imported, market foods rather than nutrient-dense, traditional, subsistence foods. ${ }^{3}$ Another related explanation is less familiarity with healthy market foods. In Alaska Native communities, subsistence foods are steeped in rich history, connecting the traditional lifestyle to the land and wildlife both physically and socially, and shaping the Alaska Native worldview. ${ }^{4}$ Imported market foods do not carry this same cultural significance, ${ }^{4}$ which may result in a lack of knowledge about how to make healthy food choices. Low population density in rural and remote Alaska Native communities ( $<1$ person per square mile) combined with a lack of affordable travel between these communities makes delivering in-person nutrition education to this population prohibitively expensive. ${ }^{5}$ Developing and testing cost-effective public health approaches to deliver nutrition education to Alaska Native people, particularly those living in rural areas, should be prioritized

\footnotetext{
${ }^{1}$ Center for Alaska Native Health Research and the Institute of Arctic Biology, University of Alaska Fairbanks, Fairbanks, AK

${ }^{2}$ Office of Public Health Studies, University of Hawai'i, Honolulu, Hawaii

Conflict of Interest Disclosure: The authors' conflict of interest disclosures can be found online with this article on www.jneb.org.

Address for correspondence: Andrea Bersamin, PhD, Center for Alaska Native Health Research, University of Alaska Fairbanks, PO Box 757000, Fairbanks, AK 99775; Phone: (907) 474-6129; Fax: (907) 474-5700; E-mail: abersamin@alaska.edu

(C)2016 Society for Nutrition Education and Behavior. Published by Elsevier, Inc. All rights reserved.
}

http://dx.doi.org/10.1016/j.jneb.2016.11.003 because of the significant health disparities experienced by this population.

Media technology such as the Internet and cell phones offers new ways to communicate about health issues and to promote health and wellbeing. According to the Pew Research Center Internet and American Life Project, ${ }^{6} 84 \%$ of American adults used the Internet in 2015 and $90 \%$ of American adults owned a cell phone in 2014. ${ }^{7}$ There is a growing body of evidence demonstrating that Web-based and computer-delivered interventions have the potential to improve knowledge and behavioral health outcomes such as physical activity, nutrition, tobacco use, and safe sexual behavior. ${ }^{8-11}$ Text messaging has also grown in popularity as an effective platform to promote health behaviors. ${ }^{12}$ Compared with traditional face-to-face counseling, technology-based nutrition education could reduce health service costs and reach a greater proportion of Alaska Native people living in rural communities. In addition, technology-based nutrition education tailored to the Alaska Native context and to an individual's readiness to change behaviors 
may increase the availability of acceptable materials for these communities. Evidence shows that nutrition education messages that are well tailored for the target population are more effective than nontailored materials in promoting behavior change. ${ }^{13}$ Because of limited access to nutrition professionals in rural Alaska, a culturally tailored technologybased approach may present the best opportunity to provide individualized nutrition education at a relatively low cost. $^{14}$

Few technology-based nutrition education programs were designed for Alaska Native populations, and the extent to which Alaska Native people living in rural Alaska use media technology is unknown. To guide the development of sustainable, technology-based health interventions, the objective of this study was to assess the use of media technology among participants of the Special Supplemental Nutrition Assistance Program for Women, Infants, and Children (WIC) living in rural Alaska Native communities. Participants in WIC are an ideal population for this study because of the potential to reach a large number of participants and their families through WIC education.

\section{METHODS}

\section{Sample}

Using a cross-sectional study design, the researchers randomly selected 975 WIC-authorized representatives in the Yukon Kuskokwim River Delta (YKD) in southwestern Alaska (48.9\%) using SPSS software (version 19.0, IBM Corporation, Armonk, NY, 2010) and mailed them a self-administered questionnaire. A WIC-authorized representative has permission to act on behalf of a WIC participant, although he or she may not be eligible for WIC benefits. The YKD is home to approximately 25,000 Alaska Native people, the majority of whom live in remote communities (population $<1,000$ ) that are accessible only by plane year round or boat in the summer. ${ }^{5}$ This region is predominantly Alaska Native $(81.5 \%)$, and more than one third of families fall below the national poverty level. The prevalence of overweight and obesity is high (>50\%), and less than $20 \%$ of the population meets daily fruit and vegetable recommenda- tions. ${ }^{5}$ This study was approved by the University of Alaska Fairbanks Institutional Review Board and the YukonKuskokwim Health Corporation Human Studies Committee.

\section{Measures}

The questionnaire included 19 items asking about current media technology use, barriers to media technology use, interest in media technology-based nutrition education, and potential barriers to media technology-based nutrition education. Survey questions were drawn from 2 national surveys and 1 survey designed to assess technology use among WIC participants with Internet access. ${ }^{15-17}$ Some study-specific questions were also added. Current practices were assessed by asking participants if they (1) owned a cell phone, smartphone, computer, DVD player, tablet, or digital camera; (2) had a text messaging plan, data plan, Internet access at home, or Internet access in their community; and (3) the frequency with which participants instant messaged, e-mailed, texted, used Facebook, used Twitter, watched videos, played games, posted videos/photos online, or participated in video calls.

Interest in media technology-based nutrition education was assessed by asking participants if they (1) thought it would be useful to obtain nutrition information on a phone or computer; (2) were interested in receiving nutrition information via e-mail, text message, Facebook, online videos, DVD/CD-ROM, online FAQs, or video chat; (3) were interested in joining an online group to talk about pregnancy, breastfeeding, parenting, fruits/vegetables, healthy beverages, picky eaters, active playtime, weight loss, or exercise; and (4) were interested in communicating with other parents about nutrition topics via e-mail, Facebook, or Twitter. A question to identify potential barriers to receiving nutrition information through media technology was included. Demographic information such as age, race, sex, education level, and participation in the Supplemental Nutrition Assistance Program was also collected.

The questionnaire was reviewed by the Yukon-Kuskokwim Health Corporation and the State of Alaska WIC Program to ensure that the content was appropriate for the target popula- tion. The questionnaire was also pilot-tested with a subsample of the population for readability.

\section{Procedures}

The Tailored Design Method guided questionnaire distribution. This method emphasizes personalizing survey materials and making several contacts with participants, via mail or the Internet, to build trust with researchers and improve response rates. ${ }^{18}$ Three contacts were made to participants via mail approximately 2-3 days apart. The first contact consisted of a postcard saying that a questionnaire would arrive and stressing the importance of the addressee's response. A few days later, potential participants received the questionnaire and a stamped and addressed return envelope, along with $\$ 2$. This was followed a few days later with a thank-you postcard and reminder to return the completed questionnaire. Participants were asked to return their completed surveys within 1 month.

\section{Data Analysis}

Frequencies were calculated to determine participant demographics and response patterns. Pearson chi-square tests were used to investigate whether Internet use, access to technologies, frequency of technology use, and perceived usefulness of technology-based nutrition education differed by age group or education level (SPSS version 19; IBM Corporation, Armonk, NY; 2010).

\section{RESULTS}

\section{Respondent Characteristics}

Of the 975 randomly selected participants, 368 (37.7\%) responded. Table 1 reports participant demographics.

\section{Media Technology: Use and Access}

Media technology use was common. Respondents reported having access to a wide variety of media technologies such as smartphones (78.8\%), tablets (44.8\%), and computers (38.4\%). Text messaging was the most frequently used media technology followed by Facebook (Figure). Of respondents who 
Table 1. Respondent Characteristics

\begin{tabular}{lr} 
Variable & \multicolumn{1}{c}{$\%$} \\
Sex, female $(\mathrm{n}=368)$ & 97.6 \\
Race $(\mathrm{n}=368)$ & \\
$\quad$ Alaska Native & 99.5 \\
White & 2.2 \\
Age, y $(\mathrm{n}=368)$ & \\
18-29 & 56.3 \\
30-49 & 37.2 \\
50-64 & 6.0 \\
$\quad \geq 65$ & 0.5 \\
Education ( $\mathrm{n}=368)$ & \\
$\quad$ Elementary & 3.3 \\
$\quad$ Some high school & 18.0 \\
$\quad$ High school graduate & 61.1 \\
$\quad$ Some college & 17.1 \\
$\quad$ College graduate & 0.5 \\
Food assistance & 57.4 \\
$\quad$ (SNAP) ( $\mathrm{n}=359)$ & \\
\hline
\end{tabular}

SNAP indicates the Supplemental Nutrition Assistance Program.

Note: Respondents were Special Supplemental Nutrition Program for Women, Infants, and Children authorized representatives living in remote, Alaska Native communities on the Yukon-Kuskokwim River Delta in southwestern Alaska.

used text messaging, 83.6\% had an unlimited text messaging plan. Of respondents who used data, $34.7 \%$ had an unlimited data plan. Altogether, 80.3\% of respondents used the Internet, and although only $42.6 \%$ of Internet users could connect from home, $75.5 \%$ could connect from somewhere in their community. Of the 63 respondents who did not use the Internet, the most common barriers to use included no Internet access (36.4\%), no computer access $(28.8 \%)$, and the high cost of Internet service $(13.6 \%)$. Only 2 respondents who did not use the Internet reported that they were just not interested (3\%).

Younger participants and participants with a higher level of education were significantly more likely to use the Internet and to have access to a smartphone (Table 2). Younger participants reported using Facebook, e-mail, and text messaging with a significantly greater frequency than older participants did. There were no differences in perceptions of usefulness among age groups or education levels.

\section{Interest in Media Technology- Based Nutrition Education}

Altogether, 85.8\% of respondents thought it would be somewhat or very useful to obtain nutrition information on a phone or computer. The most popular ways to receive nutrition information were through e-mail (67.8\%), online videos (60.4\%), Facebook (58.0\%), and text message (54.4\%) (Table 3). Potential barriers to receiving nutrition information via media technologies included slow Internet service (50.1\%), no computer access $(41.7 \%)$, and the high cost of Internet service (34.9\%).

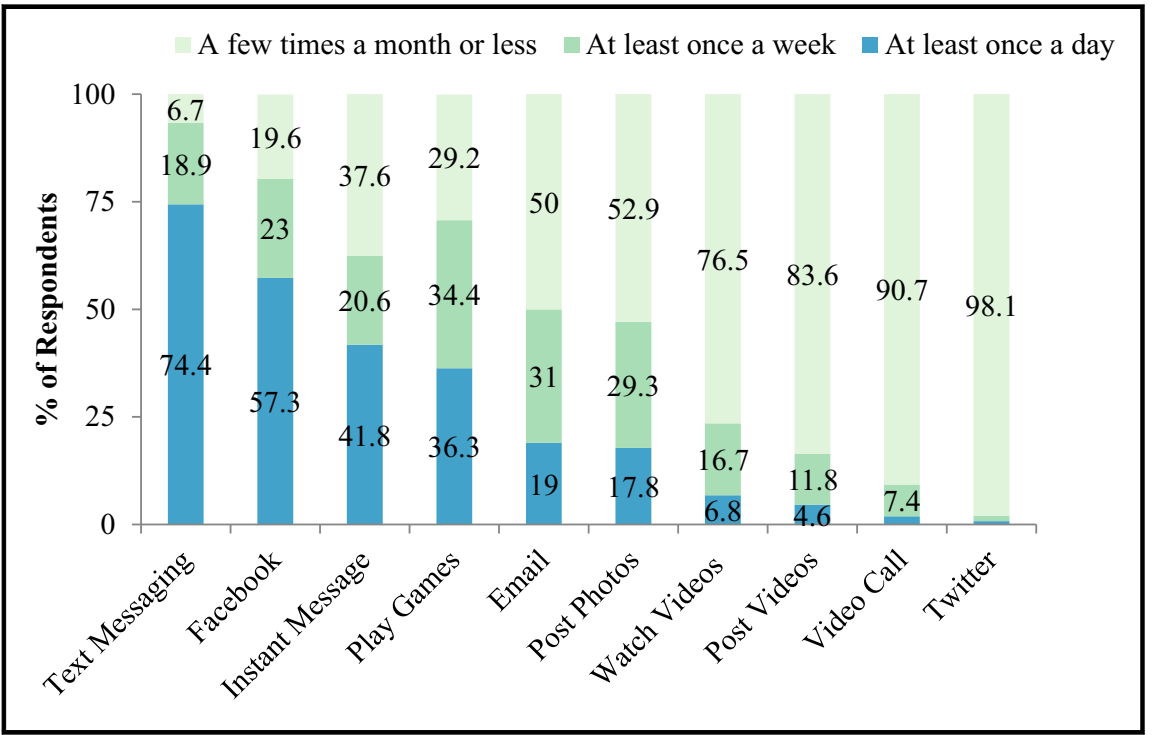

Figure. Frequency of media technology-based activities among Alaska Native Special Supplemental Nutrition Program for Women, Infants, and Children authorized representatives.

\section{DISCUSSION}

This study explored the potential of using media technology to deliver nutrition information to Alaska Native people in remote communities, a population with a recognized need for nutrition education. Overall, technology use was common among Alaska Native WIC participants in the YKD, which indicated that technology is indeed a feasible way to deliver nutrition education. In particular, the level of smartphone use was comparable to that of the general US population (78.8\% compared with $68.0 \%$ nationally). ${ }^{19}$ However, participants with smartphones were less than half as likely as the general US population to have Internet access at home (41\% compared with $90 \%$ nationally). ${ }^{20}$ In addition, only $38.4 \%$ of respondents reported having a computer, compared with $73.0 \%$ nationally. ${ }^{19}$

The finding that younger and more educated respondents were more likely to use the Internet than were older and less educated respondents is consistent with national Internet use patterns. ${ }^{6}$ That almost twice as many 18- to 29year-olds had access to a computer (40.2\%) or smartphone (83.2\%), compared with those aged $\geq 50$ years, suggested that a technology-based approach may be optimal for participants under age 30 years. Given that the WIC program serves young families (eg, pregnant women and mothers with children aged $\leq 5$ years), WIC may be ideally positioned to adopt a technology-based approach.

Alaska Native WIC participants were substantially more likely to use text messaging (93.3\% compared with $73.0 \%$ nationally), ${ }^{21}$ Facebook (80.3\% compared with $72.0 \%$ nationally), ${ }^{22}$ and some form of instant messaging (62.4\% compared with $29.0 \%$ nationally) ${ }^{22}$ than the general US population. This finding suggests that nutrition education delivered via these pathways is an ideal way to reach large numbers of Alaska Native WIC participants. In addition, high levels of Facebook and text message use are consistent in other WIC populations. ${ }^{17}$ Although respondents used texting and Facebook more frequently than e-mail, these technologies may be viewed as more recreational whereas e-mail may be viewed as more professional or work-related. However, almost one third of respondents (31.0\%) reported using e-mail at least once a 

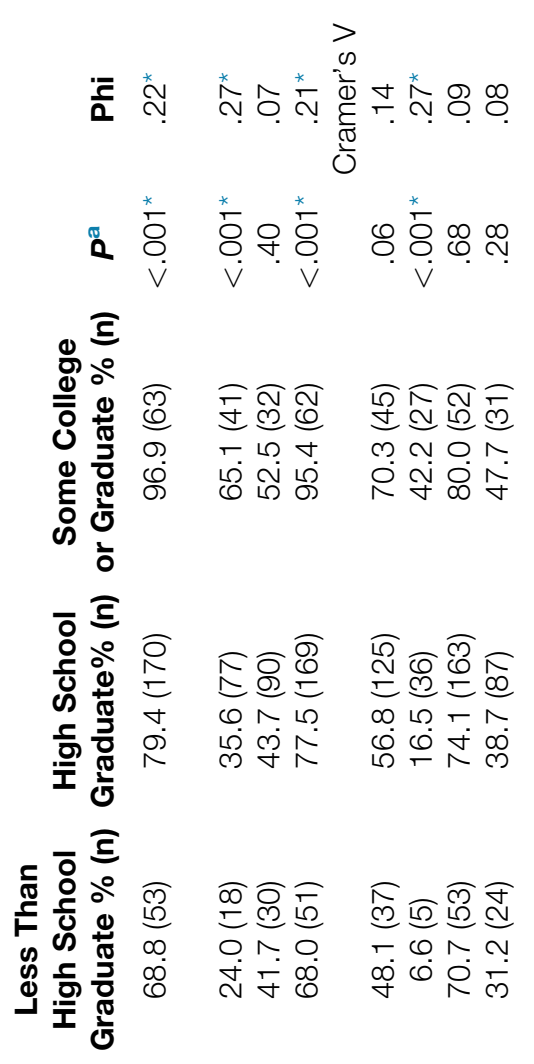

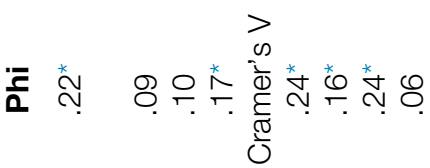

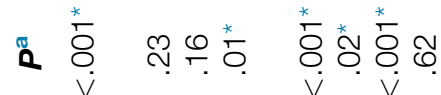

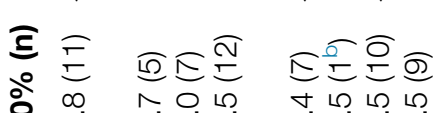

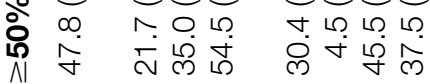

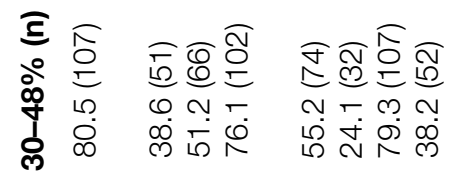

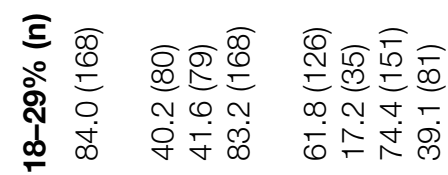

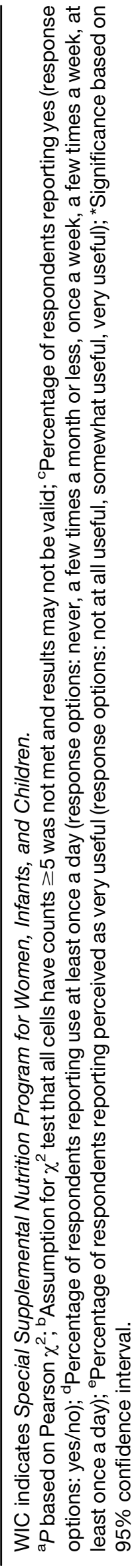

week (but less than once a day). In addition, more educated respondents used e-mail more frequently than did less educated respondents. Hence, e-mail may still be a viable way to reach many Alaska Native WIC participants, especially those with higher education levels. Because preferences vary from person to person, nutrition information should be made available through several technology channels and designed for use on mobile devices such as smartphones or tablets rather than on computers. A pilot study will need to be conducted to examine the acceptability and preliminary efficacy of these various channels.

One limitation of this study was that the survey used did not undergo reliability and validity tests. Although the survey was developed by incorporating questions from 2 national questionnaires and another administered in a WIC population, the reliability and validity of the survey could not be guaranteed. In addition, because of the anonymous nature of the survey, it was not possible to follow up with nonrespondents to identify differences from respondents. It is possible that respondents had higher literacy and higher technology use levels than nonrespondents and hence were more likely to complete the survey. Although the survey was pilot-tested for readability, a certified scale was not used. However, the 368 respondents represented about $20 \%$ of Alaska Native WIC-authorized representatives in the YKD.

Another limitation of this study was that the assumption for chi-square tests that all cells have counts greater than or equal to $n=5$ was not met for the category of WIC participants age 50 years or older who use e-mail at least once a day. Therefore, these results may not be valid. Additionally, the survey did not identify whether nutrition was a priority for participants. Hence, it was not possible to parse whether a lack of interest in technology-based education resulted from a lack of interest in nutrition information in general. It is possible that perceptions of usefulness of technologymediated information were underestimated in this study. In addition, these findings represent data from a primarily Yup'ik population and may not generalize to other Alaska Native people living in different regions of the state, or to other Native people living in different regions of the country. 
Table 3. Interest in Receiving Nutrition Education Via Various Technology Channels as Reported by Alaska Native WIC Authorized Representatives

\begin{tabular}{lcc} 
Technology Channels & $\begin{array}{c}\text { Somewhat or Very } \\
\text { Interested (\%) }\end{array}$ & $\begin{array}{c}\text { Not } \\
\text { Interested (\%) }\end{array}$ \\
$\begin{array}{l}\text { Obtaining nutrition information by phone } \\
\text { or computer }(\mathrm{n}=367)\end{array}$ & 85.8 & 14.2 \\
$\begin{array}{l}\text { Preferred channels to receive } \\
\quad \text { nutrition education: }\end{array}$ & & \\
E-mail $(\mathrm{n}=367)$ & 67.8 & 32.2 \\
Online videos $(\mathrm{n}=366)$ & 60.4 & 39.6 \\
Facebook $(\mathrm{n}=366)$ & 58.0 & 42.0 \\
Text message $(\mathrm{n}=366)$ & 54.4 & 45.6 \\
Video chat $(\mathrm{n}=367)$ & 26.4 & 73.6 \\
\hline
\end{tabular}

WIC indicates Special Supplemental Nutrition Program for Women, Infants, and Children.

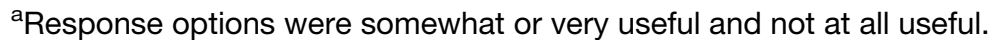

\section{IMPLICATIONS FOR RESEARCH AND PRACTICE}

Although preliminary, these findings shed light on new opportunities to reach this rural and remote population. Previous studies showed that Internetbased interventions for WIC participants increased fruit and vegetable consumption $^{23}$ and positively affected movement along stages of change for parent-child feeding behaviors. ${ }^{24}$ Hence, technology- and Internet-based nutrition education may prove effective among Alaska Native WIC participants. Because of the emphasis of WIC on family, technology-mediated nutrition information may positively affect not only WIC participants but also other family and household members. In addition, diet quality among young adult Alaska Native people tends to be lower than among older age groups in part because of a greater reliance on highly processed commercial market foods than on nutrient-rich traditional Alaska Native foods. ${ }^{3}$ Technology-mediated nutrition information targeted at younger populations could improve the reach of programs working to address this concern. This study suggests that nutrition education programs should limit the amount of cellular data necessary for participation, because cost was reported as a key barrier to Internet use. In addition, the authors believe that technology-based nutrition education in the YKD should be tailored to reflect the unique food environment in rural Alaska, incorporating traditional Alaska Native foods such as sea mammals, salmon and other fish, large land mammals, and wild plants, as well as commercial market foods into nutrition messages. ${ }^{4,25}$ Findings from this study will guide technology-based nutrition education efforts in Alaska. Future studies should develop culturally relevant nutrition messages that can be delivered via media technology, and test the feasibility of message dissemination via these newly identified technology channels. Use of media technologies in Supplemental Nutrition Assistance Program and WIC programming would support the Healthy, Hunger Free Kids Act of 2010 and the federal priority to move toward evidence-based public health approaches to promote healthy eating and an active lifestyle.

\section{ACKNOWLEDGMENTS}

The authors gratefully acknowledge the study participants, the WIC program in Bethel, Jennifer Johnson and the State of Alaska Family Nutrition Program, and the Yukon-Kuskokwim Health Corporation for their support of this project. This project would not have been possible without support from The National Institute of General Medicine Sciences Grant No. P30GM10332505 and Agriculture and Food Research Initiative Grant No. 2011-68001-30335 from the USDA National Institute of Food and Agricultural Science Enhancement Coordinated Agricultural Program.

\section{REFERENCES}

1. Jernigan VB, Duran B, Ahn D, Winkleby M. Changing patterns in health behaviors and risk factors related to cardiovascular disease among American Indians and Alaska Natives. Am J Public Health. 2010;100:677-683.

2. McLaughlin JB, Middaugh JP, Utermohle CJ, Asay ED, Fenaughty AM, Eberhart-Phillips JE. Changing patterns of risk factors and mortality for coronary heart disease among Alaska Natives, 1979-2002. JAMA. 2004;291:2545-2546.

3. Bersamin A, Luick BR, Ruppert E, Stern JS, Zidenberg-Cherr S. Diet quality among Yup'ik Eskimos living in rural communities is low: the Center for Alaska Native Health Research Pilot Study. J Am Diet Assoc. 2006;106:1055-1063.

4. Loring PA, Gerlach SC. Food, culture, and human health in Alaska: an integrative health approach to food security. Environ Sci Policy. 2008;12: 466-478.

5. State of Alaska Department of Health and Social Services, State of Alaska Family Nutrition Program, and University of Alaska Fairbanks. Alaska SNAP-Ed Needs Assessment. 2014. http://dhss.alaska.gov/ dpa/Documents/dpa/pdf/Alaska_SNAP_ needs_assessment_report.pdf. Accessed December 24, 2016.

6. Perrin A, Duggan M. Americans' Internet Access: 2000-2015. Pew Research Center. http://www.pewinternet.org/2015/06/26/ americans-internet-access-2000-2015/. Accessed December 24, 2016.

7. Pew Research Center. Mobile Technology Fact Sheet. http://www.pew internet.org/fact-sheets/mobile-technology -fact-sheet/. Accessed December 24, 2016.

8. Portnoy DB, Scott-Sheldon L, Johnson BT, Carey MP. Computerdelivered interventions for health promotion and behavioral risk reduction: a meta-analysis of 75 randomized controlled trials, 1988-2007. Prev Med. 2008;47:3-16.

9. Norman GJ, Zabinski MF, Adams MA, Rosenberg DE, Yaroch AL, Atienza AA. A review of eHealth interventions for physical activity and dietary behavior change. Am J Prev Med. 2007;33:336-345.

10. Broekhuizen K, Kroeze W, van Poppel M, Oeneme A, Brug J. A systematic review of randomized controlled trials on the effectiveness of computertailored physical activity and dietary behavior promotion programs: an update. Ann Behav Med. 2012;44:259-286. 
11. Wantland DJ, Portillo CJ, Holzemer WL, Slaughter R, McGhee EM. The effectiveness of Web-based vs. non-Web-based interventions: a meta-analysis of behavioral change outcomes. J Med Internet Res. 2004;6:e40.

12. Fjeldsoe BS, Marshall AL, Miller YD. Behavior change interventions delivered by mobile telephone short-message service. Am J Prev Med. 2009;36:165-173.

13. Campbell MK, DeVellis BM, Strecher VJ, Ammerman AS, DeVellis RF, Sandler RS. Improving dietary behavior: the effectiveness of tailored messages in primary care settings. Am J Public Health. 1994;84:783-787.

14. Brug J, Oenema A, Campbell M. Past, present, and future of computertailored nutrition education. Am J Clin Nutr. 2003;77(suppl):1028S-1034S.

15. Princeton Survey Research Associates for the Pew Internet and American Life Project. Health Care and the Internet Survey. 2000. http://www.pewinternet. org/files/old-media/Files/Questionnaire/ Old/PIP_Health_Questionnaire.pdf. Accessed December 24, 2016.
16. Princeton Survey Research Associates for the Pew Internet and American Life Project. Health Tracking Survey. 2012. http://www.pewinternet.org/files/old -media/Files/Questionnaire/2012/PIP MobileHealth2012_SurveyQuestions.pdf. Accessed December 24, 2016.

17. Bensley RJ, Hovis A, Horton KD, et al. Accessibility and preferred use of online Web applications among WIC participants with Internet access. J Nutr Educ Behav. 2014;46:S87-S92.

18. Dillman DA. Mail and Internet Surveys: The Tailored Design Method: 2007 Update. New York, NY: John Wiley \& Sons, Inc; 2007.

19. Anderson M. Technology Device Ownership: 2015. Pew Research Center. http://www.pewinternet.org/2015/10/29 /technology-device-ownership-2015. Accessed April 13, 2016.

20. Smith A. U.S. Smartphone Use in 2015. Pew Research Center. http://www.pew internet.org/2015/04/01/us-smartphone -use-in-2015/. Accessed December 24, 2016.

21. Smith A. Americans and text messaging. Pew Research Center. http://www.pew internet.org/2011/09/19/americans-and -text-messaging/. Accessed December 24, 2016.

22. Duggan M. Mobile messaging and social media 2015. Pew Research Center. http://www.pewinternet.org/2015/08/19 /mobile-messaging-and-social-media -2015/. Accessed December 24, 2016.

23. Bensley RJ, Anderson JV, Brusk JJ, Mercer N, Rivas J. Impact of Internet vs traditional Special Supplemental Nutrition Program for Women, Infants, and Children nutrition education on fruit and vegetable intake. J Am Diet Assoc. 2010;11:1723-1727.

24. Bensley RJ, Brusk JJ, Anderson JV, Mercer N, Rivas J, Broadbent LN. wichealth.org: impact of a Stages of Change-based Internet nutrition education program. J Nutr Educ Behav. 2006; 38:222-229.

25. Johnson JS, Nobmann ED, Asay E. Factors related to fruit, vegetable and traditional food consumption which may affect health among Alaska Native People in Western Alaska. Int J Circumpolar Health. 2012;71:17345.

\title{
Check Out Our New Resources for Nutrition Educators:
}

\section{Infants and Young Children/Pregnancy Collection}

\author{
http://www.jneb.org/content/collection_resources
}




\section{CONFLICT OF INTEREST}

The authors have not stated any conflicts of interest. 